\title{
A Proposed Method for the Prediction of Stability based on Actual Field Temperatures
}

\author{
Motome Terao, ${ }^{*, a}$ Katsuo Aoki, ${ }^{b}$ and Yasushi Ueki ${ }^{c}$ \\ Faculty of Pharmacy, Kinki University, a) Kowakae, Higashi-Osaka, 577, Japan, Pharmacy \\ Research Laboratories, Research and Development Division, Takeda Chemical \\ Industries, Ltd., ${ }^{b}$ Jusomotomachi, Yodogawa-ku, Osaka, 532, Japan, \\ and Computer Center, Takeda Chemical Industries, Ltd., ${ }^{c}$ \\ Jusomotomachi, Yodogawa-ku, Osaka, 532, Japan \\ (Received January 25, 1982)
}

\begin{abstract}
The present paper is concerned with an application of the annual atmospheric temperature distribution to the shelf life prediction of pharmaceutical preparations in distribution channels. The method attempts to correct for the relatively wide variation in storage temperature by utilizing actually recorded thermal histories in the respected market. The calculated storage breakdown rates obtained by this method have been found to correlate well with actual experience.
\end{abstract}

Keywords_-stability study; shelf life prediction; stability of pharmaceutical preparation; atmospheric temperature distribution; stability prediction temperature

Reliable and practical methods for stability prediction are important for the rational formulation and the quality assurance of pharmaceutical preparations during extended storage in distribution channels. Kinetic methods were introduced in this field, ${ }^{1-3}$ ) and several reports on such methods have been presented. ${ }^{4)}$ Several authors, Tootill, ${ }^{5}$ Rogers, ${ }^{6}$ Kennon, ${ }^{71}$ Lordi and Scott, ${ }^{8)}$ and Amirjahed, ${ }^{9)}$ among others, have reported practical kinetic approaches. The room temperature used in their predictions, however, was frequently only $25^{\circ} \mathrm{C}$ and the conditions of real distribution channels were not taken into account. Temperature consideration should not be limited to a fixed value such as $25^{\circ} \mathrm{C}$. It is necessary to determine what room temperature variation actually is in order to increase the accuracy of prediction.

The ultimate solution to the problem of variation in ambient storage temperature is to use the real temperatures in predicting shelf life. For this purpose, the temperature used for prediction should not, of course, be merely the arithmetical average temperature.

The problem, then, is how to use a field temperature distribution adequately. Several

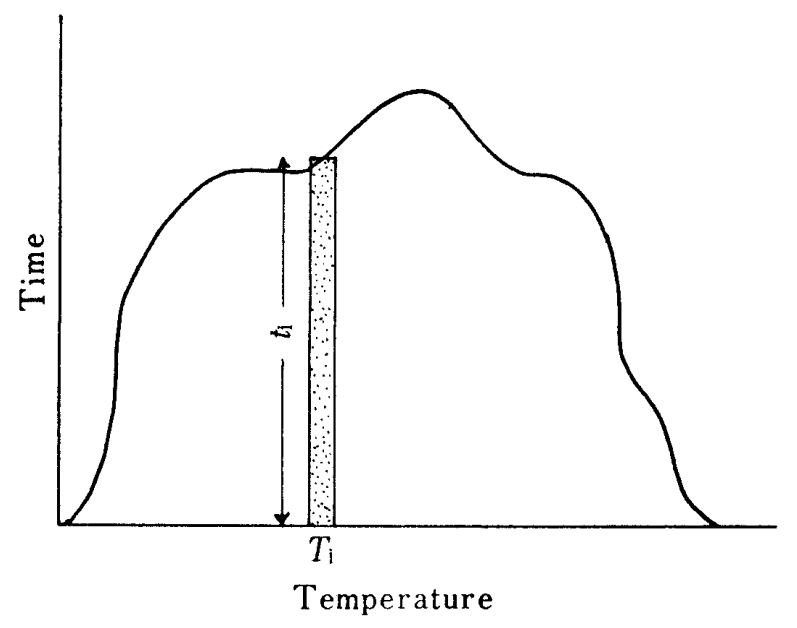

Fig. 1. A Model Atmospheric Temperature Distribution Chart attempts have been made in this direction. Terao presented a method for stability prediction utilizing atmospheric temperature distribution and predicted the stability of preservatives ${ }^{10 a}$ ) and injections ${ }^{10 b}$ ) through this method. Egawa ${ }^{11)}$ presented a method to obtain a kinetically average temperature from atmospheric temperature. In this method, however, the highest, the lowest and the annual arithmetical average values of the temperature were simply used for the calculation. Okusa $^{12)}$ reported a novel prediction method of stability, "the multilevel nonisothermal method," and a graphical calculation was employed in it. Haynes ${ }^{13)}$ 
proposed a method for calculating "the virtual temperature," which aids in the choice of a standard tempera ture for expiration dating. In these studies, the monthly arithmetical average temperatures were used for stability prediction.

In the present study, all of the temperatures and their durations in an actual field temperature distribution are exactly utilized. Therefore, the stability data predicted by this method are very accurate and compare favorably with the results of actual market storage.

\section{Theory}

Fig. 1 is a model chart of annual temperature distribution. If the concentration of a drug stored at a temperature $T_{\mathrm{i}}$ for a time $t_{\mathrm{i}}$ is represented by $C_{1}$ (initial concentration $C_{\mathrm{i}}=1$ ), and if the degradation rate of the drug is first order, then,

$$
\log C_{1}=-1 / 2.303 k_{\mathrm{i}} t_{\mathrm{i}}
$$

where $k_{\mathrm{i}}$ is the rate constant at the temperature $T_{\mathrm{i}}$.

The concentration, $C$, after storage under all of the conditions (at every temperature and time of the temperature distribution) is given by Eq. 2 :

$$
\log C=\Sigma \log C_{\mathrm{i}}
$$

Combination of Eqs. (1) and (2) gives Eq. (3):

$$
\log C=-1 / 2.303 \Sigma k_{i} t_{\mathrm{i}}
$$

Therefore, when the annual temperature distribution at a market and the rate constant at each temperature of the temperature distribution are given, the concentration of a drug after storage for one year at the market can be estimated by means of Eq. (3). In this case, the rate order has been chosen to be first order, ${ }^{14)}$ since the majority of preparations in our stability studies showed first-order degradation.

The concentration of a drug after $m$ years storage can be estimated from Eq. (4):

$$
\log C_{m}=-1 / 2.303 m \sum k_{\mathrm{i}} t_{\mathrm{i}}
$$

If $k_{\mathrm{p}}$ is the rate constant at a certain constant temperature, $T_{\mathrm{p}}$, which gives the same concentration, $C$, after time $t_{\mathrm{p}}\left(t_{\mathrm{p}}=\sum t_{1}\right)$, then Eq. (5) can be derived:

$$
-1 / 2.303 \Sigma k_{\mathrm{i}} t_{\mathrm{i}}=-1 / 2.303 k_{\mathrm{p}} t_{\mathrm{p}}
$$

Eq. (5) is further simplified to Eq. (6):

$$
\Sigma k_{\mathrm{i}} \gamma_{\mathrm{i}}=k_{\mathrm{p}}
$$

where,

$$
\gamma_{\mathrm{i}}=t_{\mathrm{i}} / t_{\mathrm{p}}
$$

If the Arrhenius equation, $\log k=\log A-E_{\mathrm{a}} / 4.574 T$, is written in exponential form, $k=A \cdot 10^{-a x}\left(X=1 / T \times 10^{3}, a=E_{\mathrm{a}}(\mathrm{kcal} / \mathrm{mol}) / 4.574\right)$, Eq. (7) can be obtained from Eq. (6) :

$$
\Sigma\left(A \cdot 10^{a x i} \cdot \gamma_{1}\right)=A \cdot 10^{-a x} p
$$

When the logarithmic value of Eq. (7) is taken and rearranged, Eq. (8) results:

$$
X_{\mathrm{p}}=\frac{\log \Sigma 10^{-a x i} \cdot \gamma_{\mathrm{i}}}{-a}
$$

Thus, the stability prediction temperature counterpart, activation energy, and time ratio can be expressed in terms of $\left(X_{p}\right),(a)$ and $\left(\gamma_{i}\right)$ respectively. $X_{p}$ corresponds to the room temperature counterpart generally used for the prediction of stability.

On the other hand, the accelerated test condition causing the same degradation as that under the atmospheric temperature distribution can also be estimated from Eq. (8). 


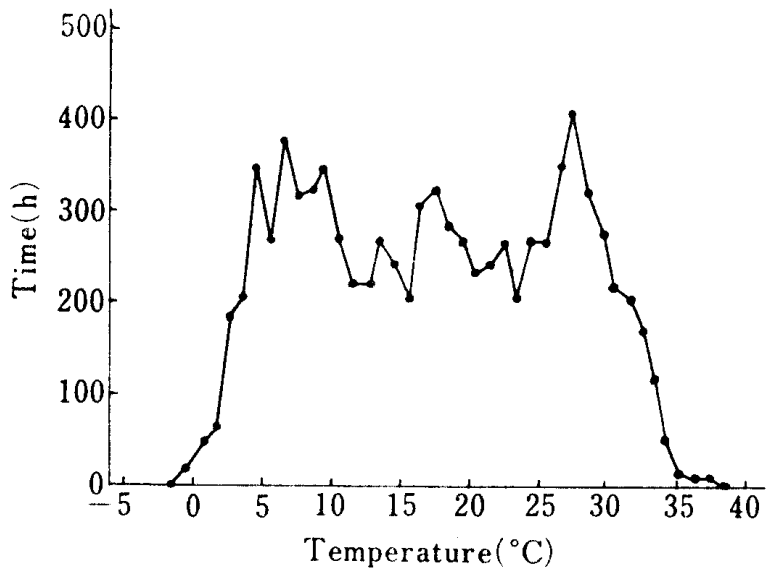

Fig. 2. Annual Atmospheric Temperature Distribution Chart measured at a Storehouse in Osaka
The time $\left(t_{\mathbf{a}}\right)$ at the accelerated temperature counterpart $\left(X_{\mathrm{a}}\right)$ which causes the same degradation as that under condition $\left(X_{\mathrm{p}}, t_{\mathrm{p}}\right)$ is given by Eq. (9):

$$
t_{\mathrm{a}}=10^{a\left(X_{\mathrm{a}}-X_{\mathrm{p}}\right)} \cdot t_{\mathrm{p}}
$$

\section{Experimental}

Annual Atmospheric Temperature Distribution Chart- The annual atmospheric temperature distribution charts at a woody plane warehouse and a reinforced concrete workshop in Osaka are shown in Iigs. 2 and 3, respectively. The temperature was measured by automatic temperature recorders (Yokogawa Electric Work and Ota Keiki). Table I shows the annual

Table I. Annual Atmospheric Temperature Distribution in Osaka

\begin{tabular}{|c|c|c|}
\hline $\begin{array}{l}\text { Temperature range } \\
\left({ }^{\circ} \mathrm{C}\right)\end{array}$ & $\begin{array}{c}\text { Mean of temperature range } \\
\left({ }^{\circ} \mathrm{C}\right)\end{array}$ & $\begin{array}{l}\text { Cumulative time } \\
\text { per year }(\mathrm{h})\end{array}$ \\
\hline$-4.0--4.9$ & -4.5 & 3 \\
\hline$-3.0--3.9$ & -4.5 & 9 \\
\hline$-2.0--2.9$ & -2.5 & 18 \\
\hline$-1.0--1.9$ & -1.5 & 48 \\
\hline$-0.1--0.9$ & -0.5 & 81 \\
\hline $0.0-0.9$ & 0.5 & 99 \\
\hline $1.0-1.9$ & 1.5 & 219 \\
\hline $2.0-2.9$ & 2.5 & 195 \\
\hline $3.0-3.9$ & 3.5 & 208 \\
\hline $4.0-4.9$ & 4.5 & 195 \\
\hline $5.0-5.9$ & 5.5 & 237 \\
\hline $6.0-6.9$ & 6.5 & 222 \\
\hline $7.0-7.9$ & 7.5 & 213 \\
\hline $8.0-8.9$ & 8.5 & 258 \\
\hline $9.0-9.9$ & 9.5 & 213 \\
\hline $10.0-10.9$ & 10.5 & 252 \\
\hline $11.0-11.9$ & 11.5 & 276 \\
\hline $12.0-12.9$ & 12.5 & 309 \\
\hline $13.0-13.9$ & 13.5 & 291 \\
\hline $14.0-14.9$ & 14.5 & 279 \\
\hline $15.0-15.9$ & 15.5 & 360 \\
\hline $16.0-16.9$ & 16.5 & 282 \\
\hline $17.0-17.9$ & 17.5 & 249 \\
\hline $18.0-18.9$ & 18.5 & 342 \\
\hline $19.0-19.9$ & 19.5 & 309 \\
\hline $20.0-20.9$ & 20.5 & 330 \\
\hline $21.0-21.9$ & 21.5 & 372 \\
\hline $22.0-22.9$ & 22.5 & 306 \\
\hline $23.0-23.9$ & 23.5 & 321 \\
\hline $24.0-24.9$ & 24.5 & 372 \\
\hline $25.0-25.9$ & 25.5 & 339 \\
\hline $26.0-26.9$ & 26.5 & 321 \\
\hline $27.0-27.9$ & 27.5 & 321 \\
\hline $28.0-28.9$ & 28.5 & 273 \\
\hline $29.0-29.9$ & 29.5 & 180 \\
\hline $30.0--30.9$ & 30.5 & 159 \\
\hline $31.0-31.9$ & 31.5 & 111 \\
\hline $32.0--32.9$ & 32.5 & 96 \\
\hline $33.0-33.9$ & 33.5 & 63 \\
\hline $34.0-34.9$ & 34.5 & 24 \\
\hline $35.0-35.9$ & 35.5 & 6 \\
\hline
\end{tabular}


atmospheric temperature distribution in Osaka (1977). Fig. 4 shows the relationship between the annual atmospheric temperature distribution chart (A, 1977, Osaka) which was determined at three-hour intervals, equivalent to Table $\mathrm{I}$, and the daily average annual atmospheric temperature distribution chart (B, 19411970, Osaka). Table II is the annual atmospheric temperature distribution in Bangkok (1969) showing a typical tropical climate. Table I, ${ }^{15)}$ Fig. $4(A),{ }^{15)}$ Fig. $4(B)^{16)}$ and Table II ${ }^{17)}$ were prepared from meteorological observatory data in each country.

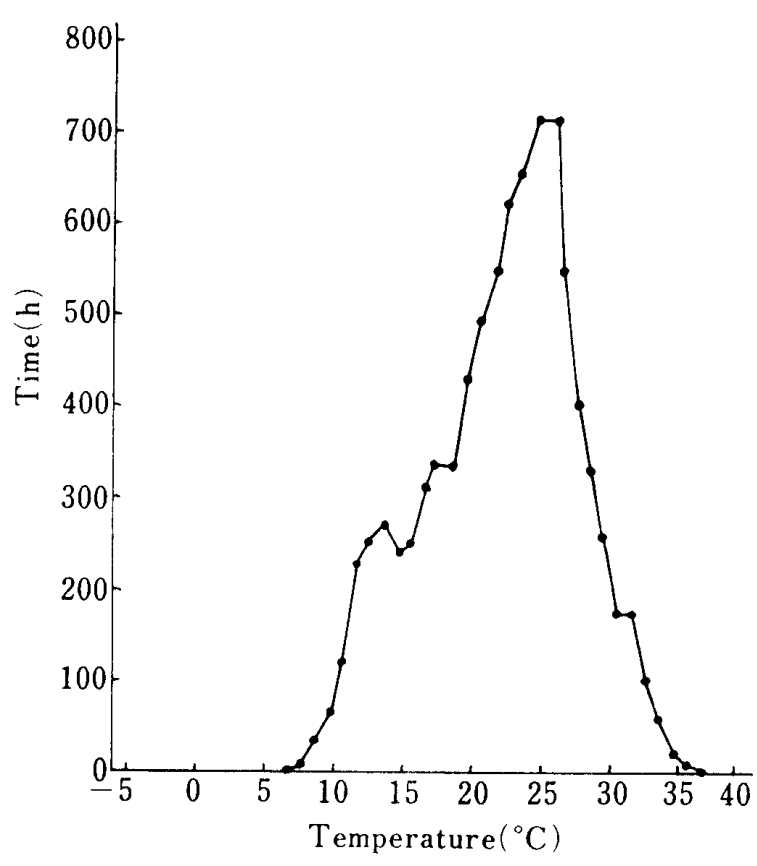

Fig. 3. Annual Atmospheric Temperature Distribution Chart measured at a Workshop in Osaka

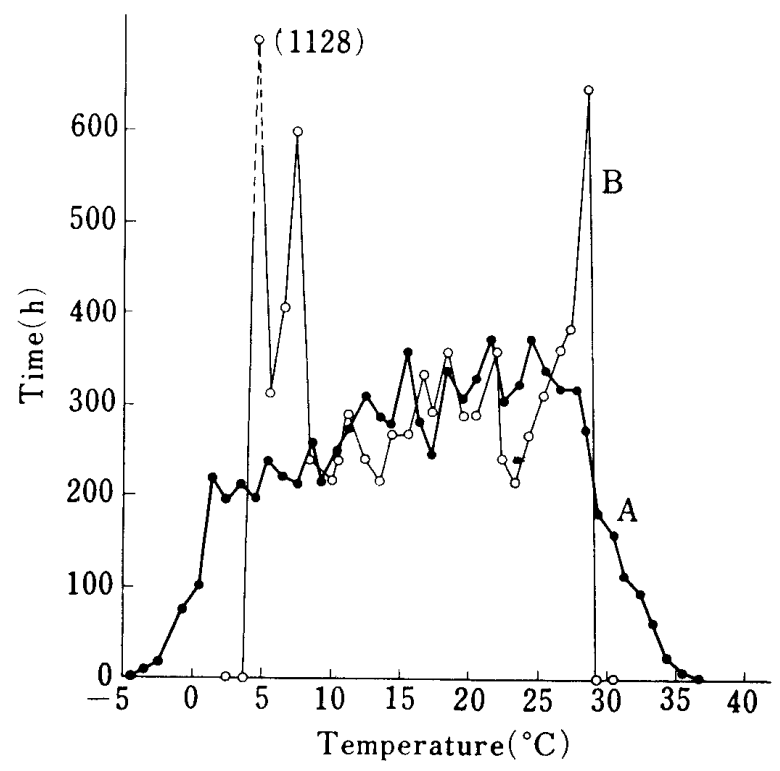

Fig. 4. Annual Atmospheric Temperature Distribution Chart derived from the Data of the Osaka Meteorological Observatory
A : cumulative curve of the annual temperature-time data measured at three-hour intervals (1977).
B: cumulative curve of the annual, daily averaged, tem- perature data $(1941-1970)$

Table II. Annual Atmospheric Temperature Distribution in Bangkok

\begin{tabular}{ccc}
\hline $\begin{array}{c}\text { Temperature range } \\
\left({ }^{\circ} \mathrm{C}\right)\end{array}$ & $\begin{array}{r}\text { Mean of temperature range } \\
\left({ }^{\circ} \mathrm{C}\right)\end{array}$ & $\begin{array}{c}\text { Cumulative time } \\
\text { per year }(\mathrm{h})\end{array}$ \\
\hline $15.0-15.9$ & 15.5 & 3 \\
$16.0-16.9$ & 16.5 & 13 \\
$17.0-17.9$ & 17.5 & 22 \\
$18.0-18.9$ & 18.5 & 56 \\
$19.0-19.9$ & 19.5 & 63 \\
$20.0-20.9$ & 20.5 & 85 \\
$21.0-21.9$ & 21.5 & 100 \\
$22.0-22.9$ & 22.5 & 128 \\
$23.0-23.9$ & 23.5 & 267 \\
$24.0-24.9$ & 24.5 & 451 \\
$25.0-25.9$ & 25.5 & 940 \\
$26.0-26.9$ & 26.5 & 1129 \\
$27.0-27.9$ & 27.5 & 1097 \\
$28.0-28.9$ & 28.5 & 1031 \\
$29.0-29.9$ & 29.5 & 850 \\
$30.0-30.9$ & 30.5 & 688 \\
$31.0-31.9$ & 31.5 & 643 \\
$32.0-32.9$ & 32.5 & 544 \\
$33.0-33.9$ & 33.5 & 365 \\
$34.0-34.9$ & 34.5 & 208 \\
$35.0-35.9$ & 35.5 & 66 \\
$36.0-36.9$ & 36.5 & 116 \\
\hline
\end{tabular}


TABLE III. Distribution of the Activation Energy Counterpart of Common Drug Compounds

\begin{tabular}{|c|c|}
\hline Compound & Activation energy counterpart \\
\hline Acetaminophen ${ }^{20)}$ & $3.7(17)$ \\
\hline Actinospectacin 211 & $4.4(20)$ \\
\hline Ampicillin 22) & $3.6(16), 4.0(18), 4.9(22)$ \\
\hline Adenine monophosphate ${ }^{23)}$ & $6.4(20)$ \\
\hline Ascorbic acid 24 & $\begin{array}{l}4.2(19), 5.5(25), 5.3(24), 5.0(23), 3.5(16), \\
5.0(23), 4.6(21)\end{array}$ \\
\hline Aspirin ${ }^{251}$ & $3.7(17), 316(16), 3.9(18), 2.7(13), 3.3(15)$ \\
\hline Atropine ${ }^{26)}$ & $\begin{array}{l}2.8(13), 3.0(14), 5.5(25), 3.8(17), 2.8(13), \\
4.6(21), 2.8(13)\end{array}$ \\
\hline Barbital27) & $5.1(24), 2.4(11), 3.3(15), 3.5(16)$ \\
\hline Benzocaine $^{28)}$ & $2.8(13), 4.0(19), 4.2(19)$ \\
\hline Benzyl penicillin ${ }^{291}$ & $3.9(18), 4.6(21), 5.0(23)$ \\
\hline Cephalothin ${ }^{30}$ & $5.0(24), 3.4(15)$ \\
\hline Chloramphenicol ${ }^{311}$ & $\begin{array}{l}5.3(24), 4.4(20), 4.6(21), 5.0(23), 5.3(24), \\
7.7(35)\end{array}$ \\
\hline Chlordiazepoxide $\left.{ }^{32}\right)$ & $5.0-5.5(23-25), 6.2(28)$ \\
\hline Chlorobutanol ${ }^{331}$ & $4.2(19), 5.6(26)$ \\
\hline Clindamycin ${ }^{34)}$ & $8.3(38), 6.4(29), 7.2(33)$ \\
\hline Diazepam ${ }^{351}$ & $4.3(20), 4.0(18), 5.0(23)$ \\
\hline Epinephrine ${ }^{36)}$ & $5.0(23)$ \\
\hline Ethylparaben ${ }^{371}$ & $4.1(19)$ \\
\hline Filipin ${ }^{8)}$ & $2.0(9)$ \\
\hline 5-Fluorouracil ${ }^{39)}$ & $5.3(24)$ \\
\hline Folic acid ${ }^{24)}$ & $3.7(17), 5.9(27), 5.1(23)$ \\
\hline Fumagillin ${ }^{24)}$ & $2.0(9), 3.7(17)$ \\
\hline Glucose $\mathrm{e}^{401}$ & $6.8(31), 7.0(32)$ \\
\hline Homatropine 26,41$)$ & $2.4(11), 2.6(12), 2.8(13)$ \\
\hline Hydrochlorothiazide $\mathbf{4}^{\mathbf{2}}$ & $5.5(25), 6.7(31)$ \\
\hline Hydroco tisone $\mathrm{24}^{4,43)}$ & $1.5(7), 3.7(17), 4.4(20)$ \\
\hline 5-Iodo-2'-deoxyuridine ${ }^{44)}$ & $6.7(30), 6.8(31), 5.9(27), 3.9(18)$ \\
\hline Isoamylnitrate ${ }^{45)}$ & $4.4(20)$ \\
\hline Lincomycin ${ }^{46)}$ & $7.0(32), 8.3(38)$ \\
\hline Methicillin ${ }^{47}$ & $3.8(17), 4.0(18)$ \\
\hline Methylparaben ${ }^{361}$ & $\begin{array}{l}4.5(20), 4.4(20), 3.3(15), 5.3(24), 4.6(21) \text {, } \\
5.6(26)\end{array}$ \\
\hline Methylphenidate ${ }^{48)}$ & $3.3(15), 5.5(25)$ \\
\hline Methylprednisolone $^{491}$ & $3.1(14)$ \\
\hline Morphine ${ }^{50)}$ & $5.0(23)$ \\
\hline Naphazoline ${ }^{511}$ & $1.1(5), 1.3(6)$ \\
\hline $2-\mathrm{PAM}^{521}$ & $3.7(17), 6.3(29)$ \\
\hline Pantothenyl alcohol ${ }^{24)}$ & $4.4(20), 4.6(21)$ \\
\hline Phenethicillin ${ }^{531}$ & $3.9(18)$ \\
\hline Phenobarbital ${ }^{54}$ & $5.6(26), 5.4(25)$ \\
\hline Pilocarpine ${ }^{551}$ & $5.5(25)$ \\
\hline Prednisolone ${ }^{56)}$ & $2.4(11)$ \\
\hline Procainamide ${ }^{28)}$ & $2.8(13)$ \\
\hline Procaine 28,57$)$ & $3.7(17), 2.6(12), 3.0(14)$ \\
\hline Propylparaben ${ }^{58)}$ & $4.3(20), 4.4(20), 2.8(13), 4.2(19)$ \\
\hline Riboflavin ${ }^{59)}$ & $4.4(20)$ \\
\hline Salicylalcohol ${ }^{60}$ & $5.3(24)$ \\
\hline Streptozotocin 24 & $4.6(21), 5.9(27)$ \\
\hline Sulfacetamide ${ }^{611}$ & $5.0(23)$ \\
\hline Thiamine $2,24,62,63)$ & 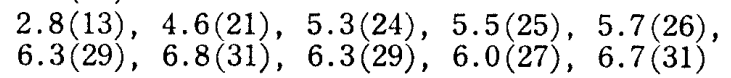 \\
\hline Thiamine propyl disulfide ${ }^{64)}$ & $5.0(23)$ \\
\hline Vitamin $\mathrm{A}^{24)}$ & $3.3(15), 5.0(23)$ \\
\hline Vitamin $B_{12}^{241}$ & $5.0(23)$ \\
\hline
\end{tabular}

Note: Numbers in parenthesis are approximate values of activation energy, $\mathrm{kcal} / \mathrm{mol}$. 
Calculation of Stability Prediction Temperature Counterpart $\left(\boldsymbol{X}_{\boldsymbol{p}}\right)$-- - An IBM 370 computer was used for the computation of Eq. (8).

Activation Energy Counterpart $(\boldsymbol{a})$-.... The activation energy counterpart of drug compounds and some adjuvants under various conditions relevant to pharmaceutical preparations were surveyed and the results are shown in Table $111 .^{20-64}$

\section{Results and Discussion}

\section{Stability Prediction Temperature}

As shown in Table III, the values of activation energy counterpart $(a)$ of the compounds related to pharmaceutical preparations mostly fall in the range of $2-8$ ( $c a .10-35 \mathrm{kcal} / \mathrm{mol}$ as activation energy). Moreover, the majority of compounds represented in Table III can be practically treated as having first-order degradation rates. Therefore, Eq. (8) is applicable in almost all cases and the calculation of Eq. (8) can be performed in the range of $a=2-8$. The values of prediction temperature counterpart, $X_{p}$, solved by computer for the atmospheric temperature distribution charts of Figs. 2 and 3 are shown by curves $A$ and $B$ in Fig. 5, respectively.

The values of prediction temperature change depending on the nature of preparations, i.e., the values of activation energy: the lower the values of $a$, the higher the values of $X_{\mathrm{p}}$. It has been made clear that the room temperature used for the prediction of stability should not be limited to one temperature only ( say $25^{\circ} \mathrm{C}$ ), but instead it should be corrected for the values of activation energy and the shape of the temperature distribution charts.

From Fig. 5 it is readily seen that the wider the range of atmospheric temperature distribution, the wider the range of prediction temperature.

The range of prediction temperature in Osaka for various preparations is regarded as $20-25^{\circ} \mathrm{C}$, which varies with the nature of the preparation. It should be reasonable for stability

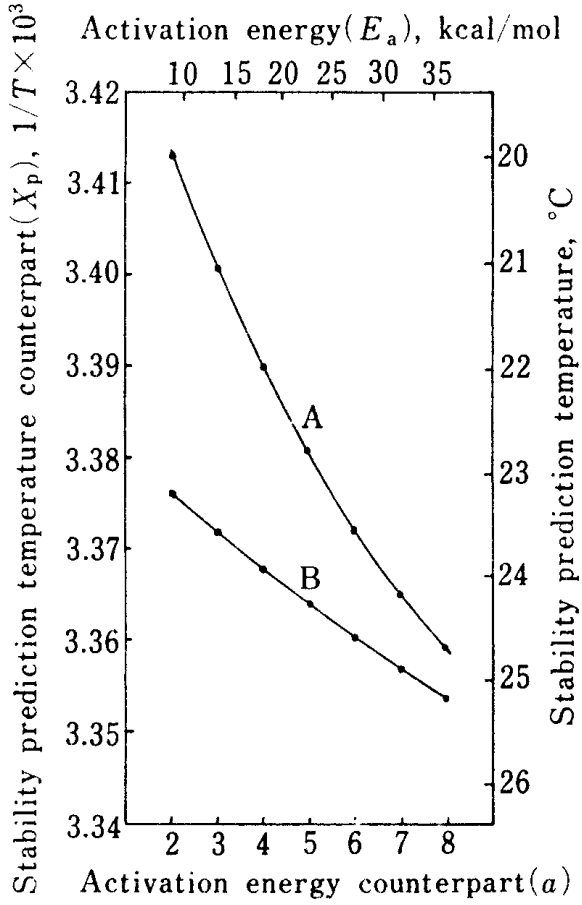

Fig. 5. Values of Stability Prediction Temperature Counterpart $\left(X_{\mathrm{p}}\right)$ for the Temperature Distribution Chart of Fig. $2(\mathrm{~A})$ and $3(\mathrm{~B})$ prediction in the domestic market to utilize the atmospheric temperature of Osaka, because the annual average temperature of Osaka $\left.\left(15.6^{\circ} \mathrm{C}, 1941-1970\right)^{17}\right)$ is the highest among the major cities in Japan (Tokyo, $15.0^{\circ} \mathrm{C}$; Yokohama, $14.8^{\circ} \mathrm{C}$; Nagoya, $14.4^{\circ} \mathrm{C}$; Kyoto, $14.8^{\circ} \mathrm{C}$; Kobe, $\left.15.5^{\circ} \mathrm{C}, 1941-1970\right)^{17}$ where large amounts of medical preparations are consumed.

As a basic parameter for stability prediction, the atmospheric temperature in some building in which the pharmaceutical preparations are handled or stored may be suitable. The atmospheric temperature data measured at meteorological observatories may be most feasible. In this case, though, the average temperature, which has an apparently biased distribution, e.g., the curve B of Fig. 4, compared to the actual distribution (curve A), should not be applied to our purpose.

\section{Prediction of Stability}

(1) Prediction of Retention Percent after One Year of Storage —-The method of prediction is illustrated by an example of thiamine in a B-complex with Cinjection. ${ }^{18)}$ The Arrhenius 
equation obtained from the accelerated stability test was as follows:

$$
\begin{aligned}
& \log k\left(\mathrm{~h}^{-1}\right)=-5.212 X+12.95 \\
& \left(N=4,{ }^{19)} X=1 / T \times 10^{3}, \sigma_{\log k}=1.01 \times 10^{-2}\right)
\end{aligned}
$$

The prediction of stability was conducted on the basis that the injection was stored in a storehouse (Fig. 2) for one year.

From Fig. 6, the value of $X_{\mathrm{p}}$ for $a=5.212$ could be read as 3.364. $X_{\mathrm{p}}=3.364$ was inserted into $X$ of the above Arrhenius equation to obtain $k=2.2624 \times 10^{-5} \mathrm{~h}^{-1}$.

The concentration, $C$, remaining after storage for one year could now be caculated from Eq. (3) $\left(t=8760 \mathrm{~h}, \mathrm{C}_{\mathrm{o}}=1\right)$, i.e., $\log C=-1 / 2.303 \Sigma k_{\mathrm{l}} t_{1}, C=0.813$. The retention rate of thiamine in the injection when stored for one year at the storehouse of Fig. 2 was therefore predicted to be $81.3 \%$. The $95 \%$ confidence interval of the retention rate was in the range of $79.3-82.9 \%$. The actual retention rate of thiamine in the injection observed after one

Table IV. Predicted Stability of Epinephrine Injection ${ }^{a)}$ at Domestic (Osaka) and Tropical (Bangkok) Atmospheric Temperatures

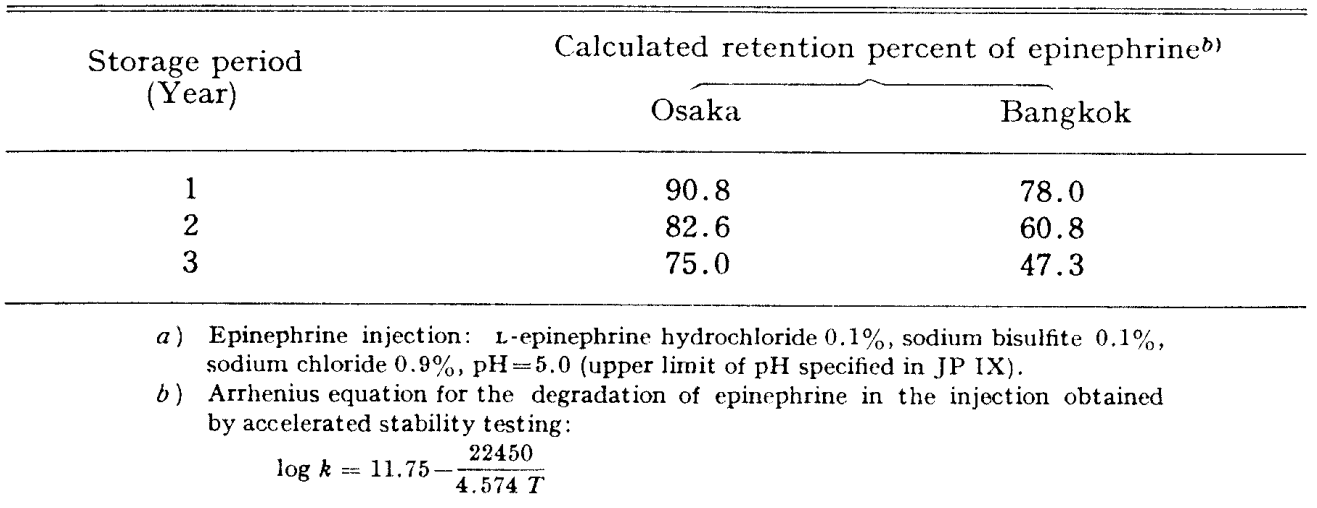

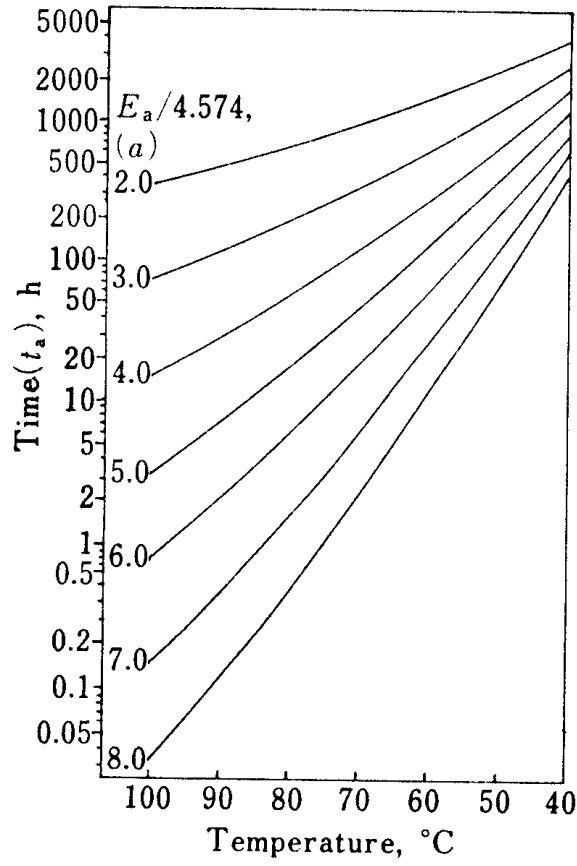

Fig. 6. Accelerated Stability Test Conditions determined by the Use of Eq. (9) and the Temperature Distribution Chart of Fig. 3 year in the storehouse was shown to be $81.0 \%$ (average of three lots.) Thus the calculated results obtained by our method compare satisfactorily with the data obtained from actual storage.

Monthly or seasonal stability prediction could also be possible by using the corresponding temperature distribution.

(2) Comparison of Stability in Different Territories - The stability of epinephrine injection containing sodium bisulfite as an antioxidant was estimated. It has already been found in an accelerated stability study that bisulfite has a destructive effect upon epinephrine ${ }^{65}$ but the long-term stability at ambient temperature of the injection is not clear.

The stability of the epinephrine injection was predicted by this method employing the temperature distributions of Tables I and II for the domestic market and tropical market, respectively. As shown in Table IV, the shelf life of the injection was estimated to be about one year in the domestic market, but it was not suitable for storage at room temperature in the 
tropical market.

(3) Design of Accelerated Stability Test Corresponding to the Actual Storage Conditions

The accelerated test conditions could be determined by the use of Eq. (9) and the temperature distribution of Fig. 3. The accelerated test conditions equivalent to the actual storage conditions are shown in Fig. 6, and appropriate test conditions could thus be selected.

Acknowledgement The authors are very grateful to Dr. T. Higuchi for his critical review of this manuscript.

\section{References and Notes}

1) A. Watanabe, Yakugaku Zassi, 59, 218 (1939).

2) E.R. Garrett, J. Am. Pharm. Assoc., Sci. Ed., 45, 470 (1956).

3) E.R. Garrett, J. Pharm. Sci., 51, 811 (1962).

4) J.A. Mollica, S. Ahuja, and J. Chohen, J. Pharm. Sci., 67, 443 (1978).

5) J.P.R. Tootill, J. Pharm. Pharmacol. 13, 75T (1961).

6) A.R. Rogers, J. Pharm. Pharmacol., 15, $101 \mathrm{~T}$ (1963).

7) L. Kennon, J. Pharm. Sci., 53, 815 (1964).

8) G. Lordi and M.W. Scott, J. Pharm. Sci., 54, 531 (1965).

9) A.K. Amirjahed, J. Pharm. Sci., 66, 785 (1977).

10) M. Terao, a) the 12 th Annual Meeting of the Pharmaceutical Society of Japan, Nagoya, April 1958; $b$ ) the 19th Annual Meeting of the Pharmaceutical Society of Japan, Tokyo, April 1964.

11) S. Egawa, the 11th Meeting of the Kinki Branch, Pharmaceutical Society of Japan, Kobe, October 1961.

12) N. Okusa, Chem. Pharm. Bull., 23, 794, 803 (1975).

13) J.D. Haynes, J. Pharm. Sci., 60, 927 (1971).

14) In cases where the rate order is zero or second order, $\log C=\sum \log \left(1-k_{i} t_{i}\right)$ or $\log C=\sum \log 1 / k_{i} t_{i}+1$, respectively.

15) Osaka Metcorological Observatory, unpublished data, 1977.

16) The Japan Meteorological Agency (ed.), "Climate Table of Japan," part 2, 1971.

17) Meteorological Department, Thailand, Monthly Meteorological Bulletin, 34, part 1, 1969.

18) The composition was as follows: thiamine hydrochloride $0.5 \%$, riboflavin sodium phosphate $0.025 \%$, niacinamide $1.0 \%$, pyridoxine hydrochloride $0.1 \%$, ascorbic acid $2.5 \%$ and benzyl alcohol $1.0 \%$. This was chosen as an example because thiamine in this solution $(\mathrm{pH}=5)$ is rather unstable.

19) It is convenient for calculation of the Arrhenius equation to equalize the intervals of $1 / T$ as $40.0,49.7$, 60.0 and $71.0^{\circ} \mathrm{C}$.

20) K.T. Kosy and J.L. Lach, J. Pharm. Sci., 50, 113 (1961).

21) E.R. Garrett and G.R. Umbreit, J. Pharm. Sci., 51, 436 (1962).

22) J.P. Hou and J.W. Poole, J. Pharm. Sci., 58, $1510(1969)$.

23) Y. Matsukura, unpublished observation.

24) E.R. Garrett, J. Pharm. Sci., 43, $539(1954) ; 45,171,470(1956) ; 49,767$ (1960); 51, 445 (1962).

25 E.R. Garrett, J. Am. Chem. Soc., 79, 3401 (1957); L.J. Leeson and A.M. Mattocks, J. Pharm. Sci., 47, 329 (1958); S.M. Blsug and J.W. Wesolowski, J. Pharm. Sci., 48, 691 (1959).

26) P. Zvirblis, I. Socholitrky, and A.A. Kondritzer, J. Pharm. Sci., 45, 450 (1956); J. L. Patel and A.P. Lemberger, J. Pharm. Sci., 48, 106 (1956).

27) J.E. Goyan, Z.I. Shaikh, and J. Autian, J. Pharm. Sci., 49, 627 (1960).

28) A.D. Marcus and S. Baron, J. Pharm. Sci., 48, 85 (1959).

29) R. Broderson, Trans. Faraday Soc., 43, 351 (1947); Acta Chem. Scand., 1, 403 (1947); Acta Pharmacol., 3, 345 (1947); J.M. Blaha, A.M. Knevel, D.P. Kessler, J.W. Mincy and S.L. Hem, J. Pharm. Sci., 65, 1165 (1976).

30) T. Yamana and A. Tsuji, J. Pharm. Sci., 65, 1563 (1976).

31) T. Higuchi and C.D. Bias, J. Pharm. Sci., 42, 707 (1953); T. Higuchi and A.D. Marcus, ibid., 43, 129, 530 (1954); A.S. Marcus and A.J. Taraszka, ibid., 48, 77 (1959).

32) A.D. Nair and J.L. Lach, J. Pharm. Sci., 48, 390 (1959); W.W. Han, G.J. Yakatan and D.D. Maness, ibid., 65, 1198 (1976).

33) K. Aoki, unpublished observation.

34) T.O. Oesterling and E.L. Rowe, J. Pharm. Sci., 59, 63, 75 (1970).

35) W. Mayer, S. Erbe, G. Wolf, and R. Voight, Pharmazie, 29, 700 (1974).

36) L.C. Schroeter and T. Higuchi, J. Pharm. Sci., 47, 426 (1958).

37) S.M. Blaug and D.E. Grant, J. Soc. Cosmet. Chem., 25, 495 (1974).

38) J.E. Tingstad and E.R. Garrett, J. Pharm. Sci., 49, 352 (1960).

39) E.R. Garrett, H.J. Nestler, and A. Somodi, J. Org. Chem., 33, 3460 (1968). 
40) N.E. Webb, G.J. Sperandio, and A.N. Martin, J. Pharm. Sci., 47, 101 (1958); K.R. Heimlich and A.N. Martin, ibid., 49, 592 (1960).

41) J.L. Patel and A.P. Lemberger, J. Pharm., 47, 878 (1958).

42) J.A. Mollica, C.R. Rehm, J.B. Smith and H.K. Govan, J. Pharm. Sci., 60, 1380 (1971).

43) A.D. Marcus, J. Pharm. Sci., 49, 383 (1960).

44) E.R. Garrett, P.B. Chemburkar, and T. Suzuki, Chem. Pharm. Bull., 13, 1113 (1965).

45) M.H. Tunker, D. Szulczewski, and T. Higuchi, J. Pharm. Sci., 47, 613 (1958).

46) T.O. Oesterling, J. Pharm. Sci., 59, 63 (1970).

47) M.A. Schwartz, E. Bara, I. Rabyez and A.P. Granatek, J. Pharm. Sci., 54, 149 (1965).

48) S. Siegel, L. Lachman, and L. Malspeis, J. Pharm. Sci., 48, 431 (1959).

49) E.R. Garrett and M.E. Royer, J. Pharm. Sci., 51, 451 (1962).

50) S. Yeh, J.L. Lach, J. Pharm. Sci., 50, 35 (1960).

51) M.J. Stern, L.D. King, and A.D. Marcus, J. Pharm. Sci., 48, 641 (1959).

52) R.I. Ellin, J.S. Carlese, and A.A. Kondritzer, J. Pharm. Sci., 51, 141 (1962).

53) M.A. Schwartz, A.P. Granatek and F.H. Buckwalter, J. Pharm. Sci., 51, 523 (1962).

54) J. Hasegawa, K. Ikeda, and T. Matsuzawa, Chem. Pharm. Bull., 6, 36 (1958).

55) M.A. Nunes and E. Brochmann-Hanssen, J. Pharm. Sci., 63, 717 (1974).

56) E.R. Garrett and M.E. Royer, J. Pharm. Sci., 51, 451 (1962).

57) T. Higuchi, A. Havinga, and L.W. Busse, J. Pharm. Sci., 39, 405 (1950).

58) A. Kamada, N Yata, K. Kubo, and M. Arakawa, Chem. Pharm. Bull., 21, 2073 (1973).

59) D.E. Guttman, J. Pharm. Sci., 51, 1162 (1962).

60) L.C. Schroeter, J. Pharm. Sci., 51, 258 (1962).

61) B. J. Meakin, I.P. Tansey, and D.J.G. Davies, J. Pharm. Pharmacol., 23, 252 (1971).

62) J.J. Windheuser and T. Higuchi, J. Pharm. Sci., 51, 354 (1962).

63) K. Aoki, unpublished observation.

64) M. Terao, unpublished observation.

65) L.C. Schroeter, T. Higuchi, and E. Schuler, J. Am. Pharm. Assoc., Sci. Ed., 47, 723 (1958). 